\title{
Stability of a phosphonic acid monolayer on aluminum in liquid environments
}

\section{AUTHOR(S):}

Hiwasa, Noboru; Utsunomiya, Toru; Ichii, Takashi; Sugimura, Hiroyuki

\section{CITATION:}

Hiwasa, Noboru ...[et al]. Stability of a phosphonic acid monolayer on aluminum in liquid environments. Japanese Journal of Applied Physics 2020, 59(SD): SDDA08.

\section{ISSUE DATE:}

2020-03-01

URL:

http://hdl.handle.net/2433/250519

\section{RIGHT:}

(C) 2019 The Japan Society of Applied Physics.; This is an author-created, un-copyedited version of an article accepted for publication in 'Japanese Journal of Applied Physics'. The publisher is not responsible for any errors or omissions in this version of the manuscript or any version derived from it. The Version of Record is available online at https://doi.org/10.7567/1347-4065/ab4ec1; The full-text file will be made open to the public on 10 December 2020 in accordance with publisher's 'Terms and Conditions for Self-Archiving'.; This is not the published version. Please cite only the published version.; この論文は出版社版でありません。引用の際には出版社版をご確認ご利用ください。 


\section{Stability of phosphonic acid monolayer on aluminum in liquid environments}

Noboru Hiwasa, Toru Utsunomiya*, Takashi Ichii, and Hiroyuki Sugimura

Department of Materials Science and Engineering, Kyoto University, Yoshida-Hommachi, Sakyo-ku, Kyoto, 606-8501 Japan.

E-mail: utsunomiya.toru.5v@kyoto-u.ac.jp

The stability of phosphonic acid self-assembled monolayers (SAMs) in water was studied on aluminum surfaces. The aim was to understand the stability of SAMs under the practical conditions that are relevant to various applications. After exposing the as-prepared alkyland fluoroalkyl-SAMs surfaces to water at $40^{\circ} \mathrm{C}$ for $2 \mathrm{~h}$, the contact angle decreased from more than $100^{\circ}$ to less than $20^{\circ}$. Thermally annealed SAMs showed larger water contact angles after exposing to water, indicating that the desorption of the molecules was depressed. 


\section{Introduction}

For developing and improving the organic devices, it is increasingly required to understand and modify the surface characteristic of materials. Self-assembled monolayers (SAMs) are single-layered organic coatings that are deposited on solid surfaces by the adsorption of organic molecules $^{1-4}$, and are known as one of the means of surface modifications for wide range of applications, such as protective films ${ }^{5-8}$, biological sensors ${ }^{9}$, and organic electronics $^{10,11}$. Appropriate selections of precursors for SAMs can aid the control of the surface characteristics of metals, oxides, and semiconductors. The typical organic molecules that form SAMs include thiols, silanes, phosphonic acids, and carboxylic acids. SAMs of phosphonic acids have been attracting attention and intensively studied because the phosphonic acid-based molecules can be easily formed into a highly dense and ordered film by the liquid phase method on various oxide surfaces including $\mathrm{Al}_{2} \mathrm{O}_{3},{ }^{12,13} \mathrm{TiO}_{2},{ }^{14}$ and $\mathrm{BaTiO}_{3},{ }^{15}$ as compared with silane-based reagents, which are highly moisture sensitive ${ }^{16}$. The easy-handling features of phosphonic acids triggers an increasing interest in phosphonic acid SAMs for device applications in many other fields, such as microelectronics and biosensors, due to their high stability in air and a thermal environment ${ }^{17-19}$.

For expanding the application fields, the stability of the formed monolayer in a liquid environment is of high practical interest for several applications, such as the construction of micropatterned ${ }^{20}$ and wettability-controlled surfaces ${ }^{21,22}$. Several researchers have examined the stability of the phosphonic acid SAMs in water at room temperature ${ }^{23,24}$. However, the stability in water at other temperature is also important for using SAMs at practical applications, such as sensors and corrosion protection coatings. Mani et al., reported the stability of phosphate and silane SAMs on Titanium in buffer solution at $37^{\circ} \mathrm{C}$ (physiological condition), and phosphate SAMs were less stable than silane SAMs ${ }^{14}$. In this study, we fabricated SAM on an aluminum foil with phosphonic acid precursors with different chain length and investigated the resistance to water and organic solvents. Aluminum and its alloys are also used in various applications. We also investigated how the process of heating after SAM deposition affects the solution resistance. To examine the stability of the SAM, the water contact angle of the prepared samples was studied after exposing to water. An additional thermal annealing process after self-assembly was also performed to obtain a strong stability of the SAMs, which helped maintain the stability of the water repellent properties $^{25}$. 


\section{Experimental methods}

Aluminum substrates were obtained from Toyo Aluminum, and cut into $20 * 20 \mathrm{~mm}^{2}$. Acetone (99.5\%, Nakalai Tesque) was used for cleaning the aluminum surface. Ethanol (99.5\% Nakalai Tesque) was used as the solvent for all phosphonic acid solutions. The phosphonic acid precursors utilized for aluminum surface modification were noctadecylphosphonic acid (ODP, STREM Chemicals), n-octylphosphonic acid (OP, Tokyo Chemical Industry), and 1H,1H,2H,2H,-Perfluorooctanephosphonic acid (PFOP, SigmaAldrich). All chemical reagents were used without further purification.

Aluminum pieces were degreased by 10 min of immersion in acetone, and then blown dry with nitrogen gas. Subsequently, the samples were kept in a vacuum ultraviolet (VUV) light treatment chamber with a Xe excimer lamp (Ushio, UER-172V) for 20 min to burn off carbonaceous contaminants. The cleaned substrates were immersed in solutions of each precursor ( $2 \mathrm{mM}$ in ethanol) for $3 \mathrm{~h}$ at room temperature. The substrates were then rinsed with ethanol to remove physisorbed molecules and dried with nitrogen gas.

The static water contact angle measurements were performed by means of the sessiledrop method using DM 500 (Kyowa). The volume of the water droplet was $1.8 \mu \mathrm{L}$ for each measurement. XPS was carried out with a ESCA-3400 (Shimadzu) using a Mg target at an acceleration voltage and current of $10 \mathrm{kV}$ and $10 \mathrm{~mA}$. The $\mathrm{C} 1 \mathrm{~s}$ hydrocarbon peak was calibrated at an electron energy of $285.0 \mathrm{eV}$. All XPS spectra were evaluated after Shirleytype background subtraction using the Casa XPS processing software.

FT-IR spectra were recorded using Excalibur FTS-3000 (Digilab Japan) with an ATR mode. A GATR (Harrick) was used to measure the surface of the modified aluminum surfaces. The samples were pressed to the Ge crystal until peaks of aluminum oxides and alkyls became visible. The screw for pressing the sample was rotated to same degree in order to keep the gap between the sample and the prism as constant. Typically, 1024 scans were taken at a resolution of $4 \mathrm{~cm}^{-1}$ for each spectrum.

\section{Results and discussion}

Self-assembled monolayers of phosphonic acids on aluminum were prepared by $3 \mathrm{~h}$ immersion of the cleaned substrates in a $2 \mathrm{mM}$ solution of each precursor in ethanol. The formation of a monolayer was probed by water contact angle measurements. Modified aluminum substrates showed water contact angles of more than $100^{\circ}$ (Fig. 1). Compared with the WCA values less than $10^{\circ}$ observed for unmodified cleaned aluminum, this indicates the successful attachment of the precursors to the aluminum surface. The WCA of 
the as-prepared samples corresponds to the literature values reported for self-assembled monolayers of alkyl and fluoroalkyl phosphonic acids on oxide surfaces ${ }^{13,26}$.

Aluminum substrates modified with SAMs were tested for their stability in water at $40^{\circ} \mathrm{C}$, ethanol at $70^{\circ} \mathrm{C}$, and acetone at $40^{\circ} \mathrm{C}$ for $2 \mathrm{~h}$. When SAMs terminated with hydrophobic groups, such as $\mathrm{CH}_{3}$ and $\mathrm{CF}_{3}$, were desorbed, a sharp decrease in contact angle values was observed. Thus, the changes in the surface wettability observed in these studies have been attributed to the loss of SAM integrity and desorption ${ }^{14}$. In hot ethanol and acetone, the water contact angles remained high for all samples. This indicates the monolayers hardly change their properties under these conditions. In contrast to the high stability in organic solvents, all as-prepared SAMs showed low stability under aqueous conditions. After immersing the samples in water at $40^{\circ} \mathrm{C}$ for $2 \mathrm{~h}$, a sharp decrease in WCA was observed for all SAMs to less than $20^{\circ}$, suggesting the desorption of the monolayer had occurred.

XPS spectra at the P2s and A12p regions were recorded before and after immersion in water for revealing the changes of $\mathrm{P}$ and $\mathrm{Al}$ peaks, as shown in Fig.2. After immersion in water, the P2s spectra showed almost complete absence of the peak around $192 \mathrm{eV}$. At A12p regions, the peak around $72 \mathrm{eV}$, which corresponds to metallic aluminum, disappeared. These changes suggested that the monolayers were detached from the surfaces, through the hydrolysis at the phosphonic acid moieties, and reaction of water to the aluminum substrate, leading to thicker oxide formation.

These results indicate that the barrier properties of the as-prepared SAMs is effective enough for hot ethanol and acetone, but is not effective for water. The incorporated water at the organic/oxide interface promotes wet delamination of organic layers, which are bound to the surface via acid-base interaction.

In order to investigate the effect of annealing, the as-prepared SAMs were thermally annealed at several temperature and time under atmospheric air. At first, the influence of the annealing temperature on the stability of the films was investigated. The as-prepared ODPSAM samples were annealed at $50,100,150,200^{\circ} \mathrm{C}$ under ambient air for $3 \mathrm{~h}$, and then the annealed samples were immersed in water at $40^{\circ} \mathrm{C}$ for $2 \mathrm{~h}$, followed by water contact angle measurements. Figure 3a shows ATR-FT-IR spectrum of the aluminum sample coated with ODP just after thermal annealing at various temperature for $3 \mathrm{~h}$. The absorption bands around 2965, 2920, 2880, and $2850 \mathrm{~cm}^{-1}$ are attributed to $v_{\mathrm{a}}\left(\mathrm{CH}_{3}\right), v_{\mathrm{a}}\left(\mathrm{CH}_{2}\right), v_{\mathrm{s}}\left(\mathrm{CH}_{3}\right)$, and $v_{\mathrm{s}}\left(\mathrm{CH}_{2}\right)$ vibrations, respectively. The methylene stretching frequencies can be an important diagnostic for the completeness and packing of the alkyl SAMs ${ }^{27,28}$. Their positions reflect the ordering of the films. After 50,100 , and $150^{\circ} \mathrm{C}$ annealing, the $v_{\mathrm{a}}\left(\mathrm{CH}_{2}\right)$ absorption band 
was observed at ca. $2921 \mathrm{~cm}^{-1}$. After $200^{\circ} \mathrm{C}$ annealing this band was shifted to higher wavenumber to ca. $2925 \mathrm{~cm}^{-1}$. This apparent existence of the peaks and the peak positions indicate that the annealed ODP-SAM samples are stable at this temperature range, but the annealing at $200^{\circ} \mathrm{C}$ induces the disordering of the SAM. It is noted that we used nonpolarized infrared radiation in these experiments. Therefore, the peak shift and the less visible peak of $v_{\mathrm{s}}\left(\mathrm{CH}_{3}\right)$ at $200^{\circ} \mathrm{C}$ cannot be attributed to the selection rules at the surface.

Figure $3 \mathrm{~b}$ shows the water contact angles of the annealed ODP SAMs after exposing water at $40^{\circ} \mathrm{C}$ for $2 \mathrm{~h}$. The largest water contact angle was obtained at $150^{\circ} \mathrm{C}$ annealing condition, indicating the enhanced stability of the SAM. SAMs annealed at $200^{\circ} \mathrm{C}$ showed decreased contact angle after exposing to water. As observed at ATR-FT-IR (Fig. 3a), the disordering the SAMs occurred at this annealing condition, leading to the less barrier properties for hydrolysis at the interface between the phosphonic acid molecules and the aluminum oxide.

Next, the influence of the annealing time was investigated. Figure $3 \mathrm{c}$ shows ATR-FT-IR spectra of the annealed ODP-SAM for the different time $(1,3,24 \mathrm{~h})$ at $150^{\circ} \mathrm{C}$. All methylene stretching regions show similar peak positions, indicating that the ordering of the SAM does not change at $150^{\circ} \mathrm{C}$ annealing condition.

Figure $3 \mathrm{~d}$ shows the water contact angles of the annealed ODP SAMs $\left(150^{\circ} \mathrm{C}\right.$ for various times) after exposing water at $40^{\circ} \mathrm{C}$ for $2 \mathrm{~h}$. The largest water contact angle was obtained at $3 \mathrm{~h}$ annealing condition, indicating the enhanced stability of the SAM. Shorter annealing of $1 \mathrm{~h}$ is also effective for stability. The prolonged annealing does not affect the stability of the ODP-SAMs apparently. Therefore, we select that annealing at $150^{\circ} \mathrm{C}$ for $3 \mathrm{~h}$ is optimal for hydrolysis resistant ODP-SAM.

XPS method is employed to further investigate the surface composition of the ODPSAM samples before and after annealing. Figure 4 shows the high resolution spectrum of $\mathrm{A} 12 \mathrm{p}$ for the ODP-SAM samples before and after annealing at $150^{\circ} \mathrm{C}$ for $3 \mathrm{~h}$. Both $\mathrm{A} 12 \mathrm{p}$ spectrum show two peaks. The small peak located at ca. $72 \mathrm{eV}$ is attributed to metallic Al. and the strong peak around $75 \mathrm{eV}$ is associated with aluminum oxide, as previously described. This identical feature implies that there is little change at the surface oxide of ODP-SAM sample after thermal annealing at $150^{\circ} \mathrm{C}$ for $3 \mathrm{~h}$ in ambient air.

We select that $150^{\circ} \mathrm{C}$ for $3 \mathrm{~h}$ annealing is optimal for stable ODP-SAM, and we also used this treatment for other SAM systems, OP and PFOP-SAMs. Figure 5 shows the water contact angles of the annealed SAM surfaces after exposing to water at $40^{\circ} \mathrm{C}$ for $2 \mathrm{~h}$. The water contact angles of annealed SAMs were almost the same as that of as-prepared samples. 
This shows that the monolayers were not ordered and desorbed through the annealing process. In the case of ODP-SAM, the contact angle remains more than $90^{\circ}$ even after $2 \mathrm{~h}$ of immersion in water. This result suggests the ODP-SAM is highly stable on the Al surface after annealing. In the case of OP and PFOP-SAM, there is a significant drop in water contact angles. This strongly suggests desorption of SAM molecules from the Al surface even after thermal annealing. Although the water contact angles of the annealed OP and PFOP-SAM decreased after exposing to water, the resulting values are larger than that of the as-prepared SAM. The thermal annealing can enhance the stability of SAM at the aqueous condition. The less stability of OP and PFOP-SAM even after thermal annealing might be explained by the less ordering of the molecules, due to the shorter chain length. The dehydration at the interface of phosphonic acid moieties and the oxides ${ }^{13}$ might be the origin of this improved stability. It is noted that several research groups used alkyl- and/or fluoroalkyl-SAMs in order to obtain the hydrophobicity on various types of aluminum oxide surfaces ${ }^{22,25,29-31}$. The pretreatments to the aluminum surface can be another factor for the stability of the phosphonic acid-based SAMs. In this study, SAMs were formed on native oxide surfaces of an aluminum foil without porous morphology and atomically controlled surface structures, which can be similar with the aluminum electrode and circuits for electronic devices. These obtained results can be important for appropriate usages of SAMs, such as corrosion control, and solution based organic device fabrications.

\section{Conclusions}

We formed phosphonic acid SAMs on an aluminum foil, and then studied their stability in liquid environments. The precursors for SAM formation were ODP, OP, and PFOP molecules. Water contact angle measurements after exposing to several liquids showed that the asprepared SAMs are stable in hot ethanol and acetone, but are desorbed in water. When the annealing process was performed to as-prepared phosphonic acid SAMs, resistance to wet delamination through hydrolysis was improved. It became clear that temperature was an important factor at annealing conditions. Our stability results in an aqueous environment are useful for producing the durable water-repellent surfaces for future applications. 


\section{References}

1) A. Ulman, Chem. Rev. 96, 1533 (1996).

2) J.C. Love, L.A. Estroff, J.K. Kriebel, R.G. Nuzzo, and G.M. Whitesides, Chem. Rev. 105, 1103 (2005).

3) B. Fabre, Chem. Rev. 116, 4808 (2016).

4) J. Veerbeek and J. Huskens, Small Methods 1, 1700072 (2017).

5) C.M. Whelan, M. Kinsella, L. Carbonell, H. Meng Ho, and K. Maex, Microelectron. Eng. 70, 551 (2003).

6) I. Maege, E. Jaehne, A. Henke, H.-J.P. Adler, C. Bram, C. Jung, and M. Stratmann, Prog. Org. Coatings 34, 1 (1998).

7) R. Zhao, P. Rupper, and S. Gaan, Coatings 7, 133 (2017).

8) T. Utsunomiya, T. Kanzawa, T. Ichii, and H. Sugimura, Thin Solid Films 638, 28 (2017).

9) S. Attavar, M. Diwekar, M.R. Linford, M.A. Davis, and S. Blair, Appl. Surf. Sci. 256, 7146 (2010).

10) O. Acton, M. Dubey, T. Weidner, K.M. O’Malley, T.-W. Kim, G.G. Ting, D.

Hutchins, J.E. Baio, T.C. Lovejoy, A.H. Gage, D.G. Castner, H. Ma, and A.K.Y. Jen, Adv. Funct. Mater. 21, 1476 (2011).

11) P.J. Hotchkiss, S.C. Jones, S.A. Paniagua, A. Sharma, B. Kippelen, N.R. Armstrong, and S.R. Marder, Acc. Chem. Res. 45, 337 (2012).

12) M. Maxisch, P. Thissen, M. Giza, and G. Grundmeier, Langmuir 27, 6042 (2011).

13) P. Thissen, M. Valtiner, and G. Grundmeier, Langmuir 26, 156 (2010).

14) G. Mani, D.M. Johnson, D. Marton, V.L. Dougherty, M.D. Feldman, D. Patel, A.A. Ayon, and C.M. Agrawal, Langmuir 24, 6774 (2008).

15) T. Schulmeyer, S.A. Paniagua, P.A. Veneman, S.C. Jones, P.J. Hotchkiss, A.

Mudalige, J.E. Pemberton, S.R. Marder, and N.R. Armstrong, J. Mater. Chem. 17, 4563 (2007).

16) J. Lee, J. Bong, Y.-G. Ha, S. Park, and S. Ju, Appl. Surf. Sci. 330, 445 (2015).

17) C. Queffélec, M. Petit, P. Janvier, D.A. Knight, and B. Bujoli, Chem. Rev. 112, 3777 (2012).

18) A. Cattani-Scholz, ACS Appl. Mater. Interfaces 9, 25643 (2017).

19) G. Guerrero, J.G. Alauzun, M. Granier, D. Laurencin, and P.H. Mutin, Dalt. Trans. 42, 12569 (2013).

20) H. Sugimura, H. Sano, K.-H. Lee, and K. Murase, Jpn. J. Appl. Phys. 45, 5456 (2006). 
21) T. Fujii, H. Sato, E. Tsuji, Y. Aoki, and H. Habazaki, J. Phys. Chem. C 116, 23308 (2012).

22) B. Ding, T. Ogawa, J. Kim, K. Fujimoto, and S. Shiratori, Thin Solid Films 516, 2495 (2008).

23) N.S. Bhairamadgi, S.P. Pujari, F.G. Trovela, A. Debrassi, A.A. Khamis, J.M. Alonso, A.A. Al Zahrani, T. Wennekes, H.A. Al-Turaif, C. van Rijn, Y.A. Alhamed, and H. Zuilhof, Langmuir 30, 5829 (2014).

24) M. Kosian, M.M.J. Smulders, and H. Zuilhof, Langmuir 32, 1047 (2016).

25) K. Nakayama, E. Tsuji, Y. Aoki, and H. Habazaki, RSC Adv. 4, 30927 (2014).

26) X. Chen, E. Luais, N. Darwish, S. Ciampi, P. Thordarson, and J.J. Gooding, Langmuir 28, 9487 (2012).

27) R. Haasch, R.G. Nuzzo, D.B. Wolfe, M.L. Chabinyc, K.E. Paul, and G.M. Whitesides, J. Am. Chem. Soc. 125, 2597 (2003).

28) A.I.A. Soliman, T. Utsunomiya, T. Ichii, and H. Sugimura, Langmuir 34, 13162 (2018).

29) T. Fujii, Y. Aoki, and H. Habazaki, Langmuir 27, 11752 (2011).

30) K. Nakayama, E. Tsuji, Y. Aoki, S.-G. Park, and H. Habazaki, J. Phys. Chem. C 120, 15684 (2016).

31) A. Debrassi, A. Ribbera, W.M. de Vos, T. Wennekes, and H. Zuilhof, Langmuir 30, $1311(2014)$. 


\section{Figure Captions}

Fig. 1. Water contact angles of ODP, OP, and PFOP-SAM after immersing various liquids.

Fig. 2. XPS spectra of (a) P2s and (b) A12p regions at the as-prepared ODP-SAM surface before and after immersion in water.

Fig 3. (a) FT-IR spectra of the ODP-SAM samples at the methylene stretching region after annealing for $3 \mathrm{~h}$ at various temperature. (b) Water contact angles of the thermally annealed ODP-SAM samples after immersing in water. (c) FT-IR spectra of the ODP-SAM samples at the methylene stretching region after annealing at $150^{\circ} \mathrm{C}$ for prolonged time. (d) Water contact angles of the thermally annealed ODP-SAM samples after immersing in water.

Fig. 4. The XPS spectra at A12p regions of ODP-SAM samples before and after annealing.

Fig. 5. Water contact angles of the ODP, OP, and PFOP-SAM samples with and without annealing after immersion in water. 


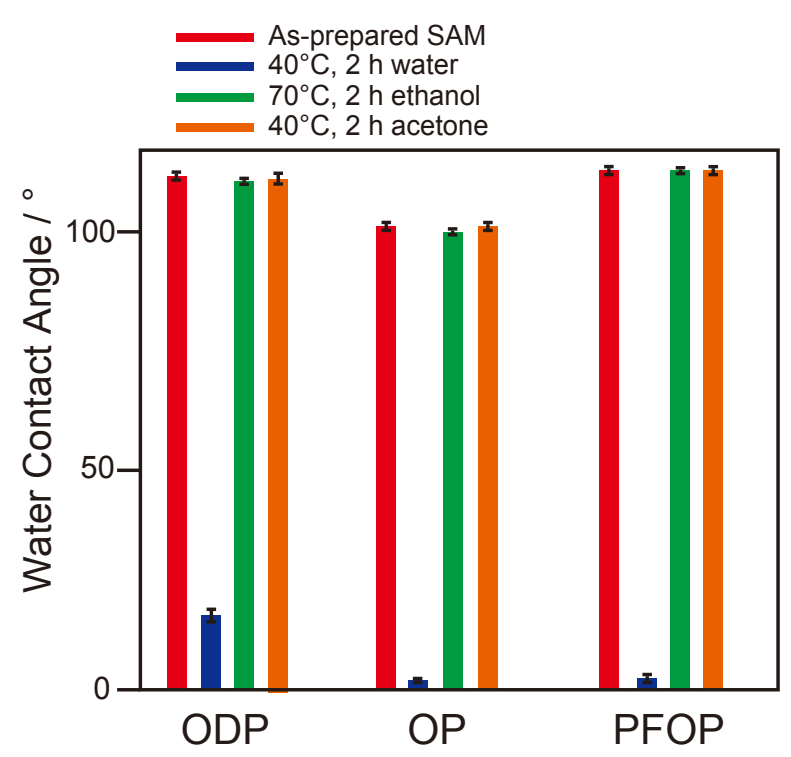

Fig. 1. Water contact angles of ODP, OP, and PFOP-SAM after immersing various liquids.

(a)

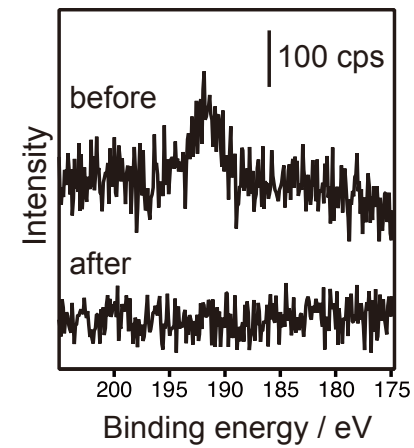

(b)

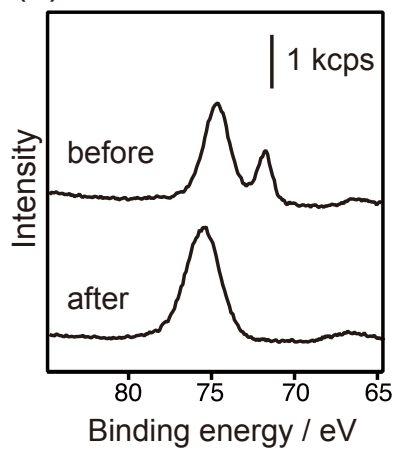

Fig. 2. XPS spectra of (a) P2s and (b) A12p regions at the as-prepared ODP-SAM surface before and after immersion in water. 
(a)

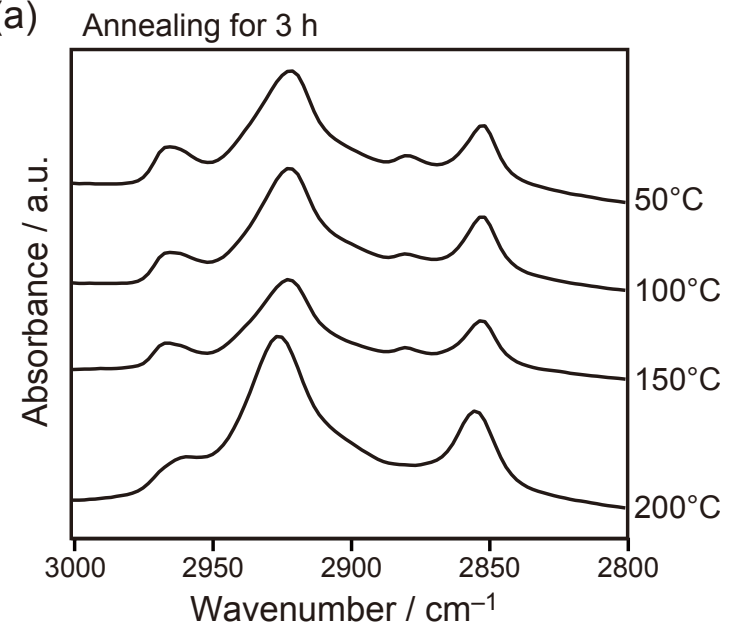

(b)

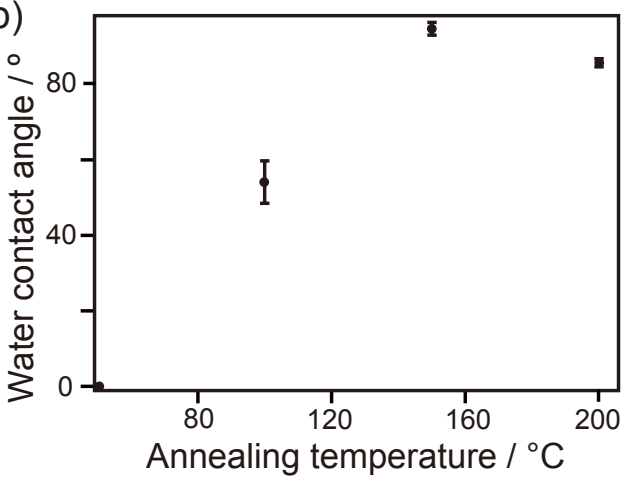

(c) Annealing at $150^{\circ} \mathrm{C}$
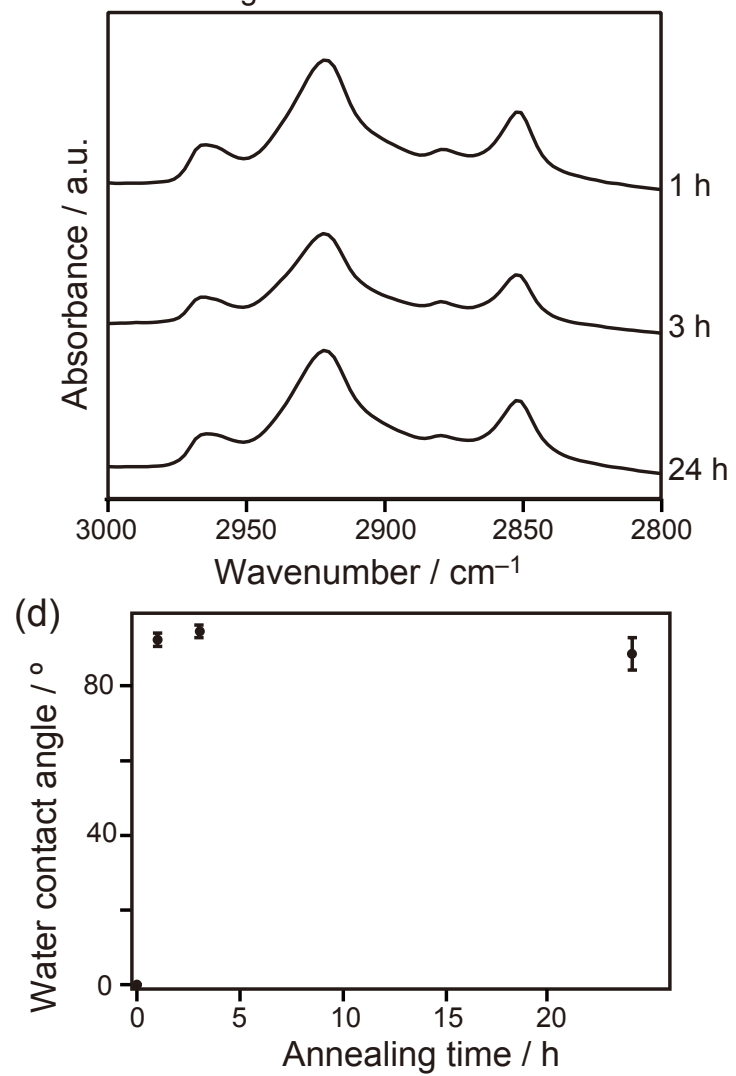

Fig 3. (a) FT-IR spectra of the ODP-SAM samples at the methylene stretching region after annealing for $3 \mathrm{~h}$ at various temperature. (b) Water contact angles of the thermally annealed ODP-SAM samples after immersing in water. (c) FT-IR spectra of the ODP-SAM samples at the methylene stretching region after annealing at $150^{\circ} \mathrm{C}$ for prolonged time. (d) Water contact angles of the thermally annealed ODP-SAM samples after immersing in water. 


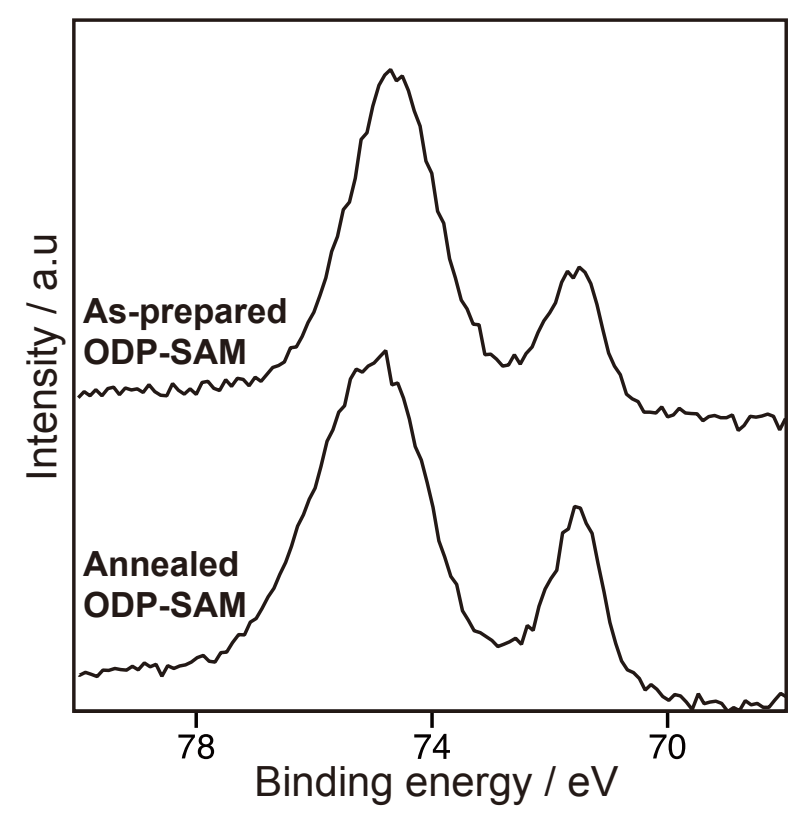

Fig. 4. The XPS spectra at Al2p regions of ODP-SAM samples before and after annealing.

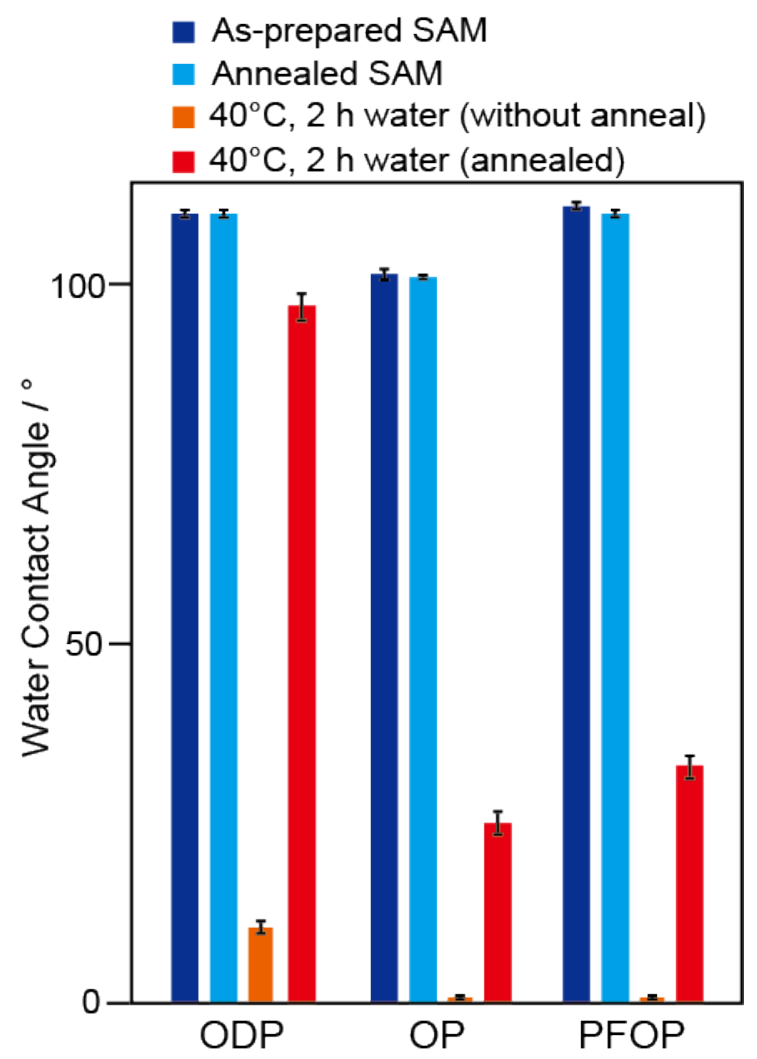

Fig. 5. Water contact angles of the ODP, OP, and PFOP-SAM samples with and without annealing after immersion in water. 